\title{
EVALUATION OF PATIENTS WITH INVASIVE BREAST CARCINOMA SUBMITTED TO NEOADJUVANT CHEMOTHERAPY ATTENDED AT DR ARNALDO VIEIRA DE CARVALHO CANCER INSTITUTE FORM 2006 TO 2014
}

Fábio F. O. Rodrigues', Eveline A. Silva', Etienne A. Bastos¹, Daniel C. B. de Oliveira', Rodrigo M. Silva', Carlos E. Fristachi 'Oncoginecology and mastology service, Instituto de Câncer Dr. Arnaldo - São Paulo (SP), Brazil.

Objectives: Evaluate the characteristics of patients with invasive breast carcinoma submitted to neoadjuvant chemotherapy attended at the Oncoginecology and Mastology service of Dr. Arnaldo Vieira de Carvalho Cancer Institute form 2006 to 2014. Methods: A retrospective, descriptive, longitudinal study was performed of patients with invasive breast carcinoma attended at ICAVC in São Paulo; data were analyzed on the database of Microsoft Excel ${ }^{\circledR}$. Results: 339 patients were evaluated, of which 57 (17\%) underwent adjuvant chemotherapy with predominance of patients with tumors T3 (47.4\%), DCI (91.2\%) and luminal (72\%). The main regimen used was anthracycline in association with taxane (66.7\%); 14\% patients presented complete clinical-pathological response (pCR); $21 \%$ underwent conservative surgery; $3.5 \%$ presented local recurrence and $24.6 \%$ presented distant metastasis in the mean period of 2 years (disease-free survival). Overall survival was 10 years. Conclusion: Neoadjuvant chemotherapy was shown in this study as a treatment of choice in locally advanced tumors targeting $\mathrm{pCR}$ with increased conservative breast surgeries. 